\title{
Influência da energia de compactação no comportamento volumétrico e mecânico de misturas asfálticas
}

\author{
Lílian Tais de Gouveia'; José Leomar Fernandes Júnior²; Jorge Barbosa Soares³
}

\begin{abstract}
Resumo: Agregados angulares e rugosos apresentam maior resistência à compactação que agregados de angularidade baixa e textura lisa. Uma maneira apropriada de vencer essa resistência à compactação é aumentar a energia de compactação aplicada. Nesta pesquisa, foram investigadas as energias de compactação de 75, 110 e 155 golpes, aplicadas com o soquete Marshall, e seus efeitos nas propriedades volumétricas e mecânicas das misturas. Os resultados mostram que o aumento da energia de compactação promove arranjos melhores entre partículas, ocorrendo diminuição do VAM e elevação da estabilidade e rigidez das misturas, sem prejuízos à vida de fadiga. Observou-se que a vida de fadiga aumenta ao ser aplicada energia correspondente a 110 golpes, o que constitui uma evidência favorável à hipótese de que pode haver melhor desempenho se as misturas asfálticas constituídas por agregados angulosos e rugosos forem compactadas com energia superior à que convencionalmente é aplicada no método de dosagem Marshall.
\end{abstract}

Abstract: Angular and rough aggregates present greater compaction resistance than aggregate of low angularity and smooth surface texture. An appropriate way to overcome this compaction resistance is to increase the compaction energy. In this research, it was evaluated the compaction energy of 75, 110 and 155 blows, applied with Marshall hammer, and its effects on the volumetric and mechanical properties of the mixtures. The results show that the increase in the level of compaction energy employed builds better arrangements between particles and allows the reduction of the VMA and the increase of the stability and stiffness, without reducing the fatigue life of the mixtures. It was observed that the fatigue resistance increases with compaction energy of 110 blows. Therefore, there is evidence that a better behavior can be achieved by the increase of compaction energy in asphalt mixtures produced with angular and rough aggregates.

\section{INTRODUÇÃO}

O pavimento pode ser entendido como um sistema de camadas sujeito às cargas de veículos, que causam tensões, deformações e deslocamentos. Como parte integrante desse sistema tem-se a camada de revestimento, responsável por receber a ação do tráfego e propiciar comodidade e segurança àqueles que trafegam pela via.

A grande maioria das rodovias pavimentadas no Brasil é revestida por concreto asfáltico usinado a quente, cujo desempenho depende das propriedades e proporções relativas de seus componentes principais, ou seja, agregado, asfalto e vazios. Os agregados compõem de 80 a $90 \%$ do volume total das misturas e têm como função principal formar seu esqueleto estrutural, responsável por resistir à compressão e ao movimento das cargas dos veículos (Cross \& Brown, 1992; Kim et al., 1992). O ligante asfáltico tem como finalidade principal envolver as partículas de agregado, fazendo com que permaneçam unidas após a compactação. Já os vazios são necessários como parte in-

\footnotetext{
${ }^{1}$ Lilian Tais de Gouveia, Universidade de São Paulo, Escola de Engenharia de São Carlos. São Carlos, SP, Brasil. (e-mail: Itgouveia@gmail.com).

${ }^{2}$ José Leomar Fernandes Júnior, Universidade de São Paulo, Escola de Engenharia de São Carlos. São Carlos, SP, Brasil. (email: leomar@sc.usp.br).

${ }^{3}$ Jorge Barbosa Soares, Universidade Federal do Ceará. Santa Catarina. Fortaleza, CE, Brasil. (e-mail: jsoares@det.ufc.br).
}

Manuscrito recebido em 5/7/2007 e aprovado para publicação em 9/10/2007. Este artigo é parte de TRANSPORTES, volume XV, número 1, junho de 2007. ISSN: 1415-7713. tegrante das misturas para evitar a exsudação de asfalto e o conseqüente fluxo plástico.

A formação do esqueleto estrutural está relacionada à quantidade de energia de compactação aplicada, assim como às características de superfície dos agregados (forma, angularidade e textura superficial), para misturas produzidas numa mesma granulometria (Masad et al., 1999; Yue et al., 1995).

Agregados angulares e com textura superficial rugosa produzem misturas com esqueletos estruturais menos densos, ou seja, com valores de vazios do agregado mineral (VAM) elevados, devido à maior resistência à compactação imposta por partículas com essas características (Gouveia, 2006). Essa maior resistência à compactação fora demonstrada por Anderson \& Bahia (1997) quando correlacionaram o VAM com a inclinação da curva de densificação da mistura, utilizando o compactador giratório Superpave (CGS). A inclinação da curva de densificação, que é indicativa da resistência à compactação da mistura, mostrouse mais elevada quanto maior a angularidade e rugosidade dos agregados utilizados.

A elevação da energia de compactação aplicada à mistura é vista como uma maneira apropriada de vencer essa resistência à compactação mais elevada imposta por agregados mais angulares e rugosos. No entanto, na compactação Marshall são especificados apenas três níveis de compactação possíveis: 35,50 e 75 golpes. Essa limitação impossibilita a diminuição do VAM de misturas produzidas com agregados angulares e rugosos através de um maior esforço de compactação e pode dissimular as reais potencialidades 
mecânicas dessas misturas.

Neste contexto, tomou-se a decisão de investigar mais detalhadamente no presente trabalho a influência do grau de compactação nas propriedades volumétricas e mecânicas das misturas, variando-se gradativamente a energia de compactação de 75 golpes para 110 golpes e, então, para 155 golpes, aplicados pelo soquete Marshall. Os estudos foram desenvolvidos com base na hipótese de que as misturas produzidas com agregados angulares e rugosos (mais difíceis de serem compactados) poderiam ser mais compactadas, reduzindo o VAM, de maneira a melhorar o arranjo estrutural das partículas e, portanto, melhorar as propriedades mecânicas das misturas.

\section{EXPERIMENTOS LABORATORIAIS}

\subsection{Materiais utilizados}

Foram utilizados dois tipos de agregados, um gabro, proveniente da Pedreira São Roque, localizada em Limeira-SP, e um basalto, proveniente da Pedreira Santa Isabel, localizada na cidade de Ribeirão PretoSP. O asfalto utilizado foi um CAP 20, cujas propriedades estão em conformidade com as exigências contidas no Regulamento Técnico ANP 3/2005, sendo classificado como um CAP 50/70 de acordo com as novas especificações nacionais vigentes desde julho de 2005 .

\subsection{Produção dos corpos de prova}

Utilizando-se uma única curva granulométrica (Tabela 1), foram produzidas misturas Marshall com o agregado de gabro (AZRg) e basalto (AZRb), compactadas com 75, 110 e 155 golpes por face, sendo determinados os teores de projeto para cada nível de compactação.

A Figura 1 ilustra como foi o procedimento de escolha das energias de compactação correspondentes a 110 e 150 golpes por face do corpo de prova. Pode-se verificar que foi mantida a mesma proporção de aumento dos níveis de energia de compactação já adotada no Método Marshall.

Tabela 1. Curva granulométrica utilizada

\begin{tabular}{cc}
\hline Abertura das peneiras $(\mathbf{m m})$ & Porcentagem passante \\
\hline 19,000 & 100 \\
12,500 & 95 \\
9,500 & 86 \\
4,750 & 61 \\
2,360 & 45 \\
1,180 & 35 \\
0,600 & 26 \\
0,300 & 19 \\
0,150 & 11 \\
0,075 & 3,5 \\
\hline
\end{tabular}

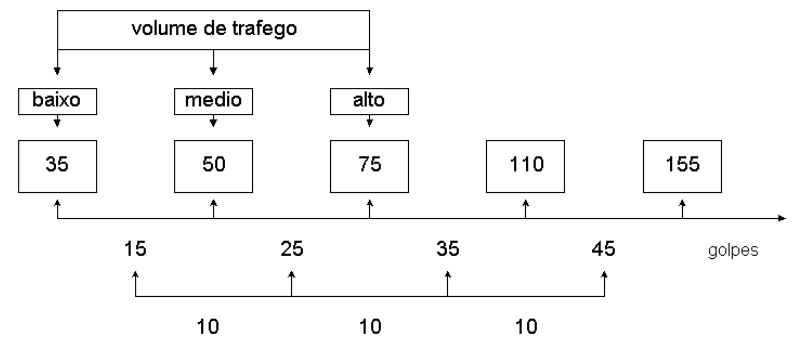

Figura 1. Procedimento de escolha das energias de compactação correspondentes a 110 e 155 golpes por face do corpo de prova Marshall

As misturas foram produzidas com apenas um tipo de agregado (gabro ou basalto) em suas frações grossa e fina. Como fíler (material passante na peneira $0,075 \mathrm{~mm}$ ), foi utilizado pó de areia natural em todas as misturas, objetivando eliminar influência desse material nos resultados. A temperatura de aquecimento do asfalto utilizado foi de $160^{\circ} \mathrm{C}$, correspondente a uma viscosidade Saybolt-Furol de 85 segundos, determinada a partir da curva de viscosidade versus temperatura. A temperatura de compactação da mistura foi mantida a $146^{\circ} \mathrm{C}$, correspondente a uma viscosidade Saybolt-Furol de 130 segundos. Essa temperatura encontra-se dentro da faixa limite especificada para a temperatura de compactação, na qual o ligante deve apresentar uma viscosidade Saybolt-Furol de 140 15 segundos, como estabelece a norma NBR 12891.

Após o processo de mistura do agregado com o asfalto, realizado individualmente na confecção de cada corpo de prova, a massa asfáltica resultante de cada mistura foi colocada em uma vasilha de alumínio e levada à estufa, onde permaneceu por 2 horas na temperatura de compactação (período de cura), conforme estabelece a norma AASHTO PP2. Em seguida, iniciou-se a compactação dos corpos de prova com energia de 75, 110 e 155 golpes por face. Após a compactação, os corpos de prova permaneceram em seus moldes metálicos, em temperatura ambiente, até o resfriamento da mistura, para que, no momento da extração de seus moldes, tivessem consistência suficiente para evitar deformações. Terminada a extração, os corpos de prova foram deixados em temperatura ambiente, por aproximadamente 12 horas, para, então, ser determinada a densidade aparente da mistura utilizando o método de secagem superficial (AASHTO $\mathrm{T}$ 166).

\subsection{Métodos de análise das propriedades de forma, angularidade e textura}

Nesta pesquisa, as propriedades de forma, de angularidade e de textura superficial dos agregados foram determinadas através dos seguintes ensaios:

- Porcentagem de partículas fraturadas em agregados grossos (ASTM D 5821);

- Porcentagem de partículas planas, alongadas e 




Figura 2. Tabela de Russel \& Taylor-graus de arredondamento: angular, subangular, subarredondado, arredondado, bem arredondado (Suguio, 1973)

planas e alongadas em agregados grossos (ASTM D 4791);

- Análise visual comparativa do grau de angularidade do agregado grosso, utilizando a tabela de Russel \& Taylor (Figura 2);

- Angularidade do Agregado Fino (Método A ASTM C 1252);

- Análise visual comparativa da angularidade do agregado fino, utilizando a tabela de Russel \& Taylor (Figura 2);

- Análise visual comparativa do grau de esfericidade do agregado fino, utilizando a tabela de Rittenhouse (Figura 3).

Para a realização das análises visuais, as partículas foram separadas por tamanhos, usando a mesma seqüência de peneiras apresentadas na Tabela 1, sendo posteriormente examinadas uma a uma e comparadas com as classes de graus de arredondamento (Figura 2) e de esfericidade (Figura 3). A textura superficial foi avaliada visualmente e classificada como lisa ou rugosa.

\subsection{Métodos de análise usados na avaliação das propriedades mecânicas}

As propriedades mecânicas das misturas foram avaliadas por meio dos seguintes ensaios mecânicos: (i) estabilidade e fluência Marshall (ABNT NBR 12891), (ii) fluência por compressão uniaxial dinâmica, (iii) resistência à tração por compressão diametral estática (DNER ME 138), (iv) módulo de resiliência por compressão diametral dinâmica e (v) fadiga por compressão diametral dinâmica.

O ensaio de fluência por compressão uniaxial dinâ-



Figura 3. Tabela de Rittenhouse - graus de esfericidade bidimensional (Suguio, 1973)

mica foi realizado com a aplicação de 5.000 ciclos de carregamento, tensão de compressão de $0,1 \mathrm{MPa}$ e temperatura de $40^{\circ} \mathrm{C}$. Já o ensaio de módulo de resiliência foi realizado aplicando-se 500 ciclos, com magnitude de carga entre 20 e $25 \%$ da resistência à tração e calculado com base na curva de deformação para cada ciclo de carregamento. $\mathrm{O}$ ensaio de fadiga foi realizado sob o regime de tensão controlada, com carga correspondente a 20,30 e $40 \%$ da resistência à tração e temperatura de $25^{\circ} \mathrm{C}$. Utilizou-se como critério de parada do ensaio a ruptura do corpo de prova ou deformação vertical máxima de $4 \mathrm{~mm}$. Cada ciclo de carregamento, acima citado, é composto por $0,1 \mathrm{~s}$ de aplicação de carga e $0,9 \mathrm{~s}$ de descanso, com freqüência de $60 \mathrm{ciclos} / \mathrm{min}$.

\section{RESULTADOS}

\subsection{Análise de quebra de partículas}

Para verificar a ocorrência de quebra de partículas, avaliou-se a granulometria das misturas após a compactação. Após a extração de asfalto da mistura com posterior peneiramento do agregado no mesmo conjunto de peneiras utilizado neste estudo (Tabela 1), foram obtidas as curvas granulométricas apresentadas na Figura 4, plotadas junto com a curva granulométrica original da mistura AZR. Os resultados mostram que as porcentagens de quebra foram baixas, tanto para o agregado de gabro quanto para o agregado de basalto, o que vem corroborar os resultados bons de abrasão Los Angeles encontrados, de 18,3\% e 16,2\%, respectivamente. Pode-se observar, também, que o 


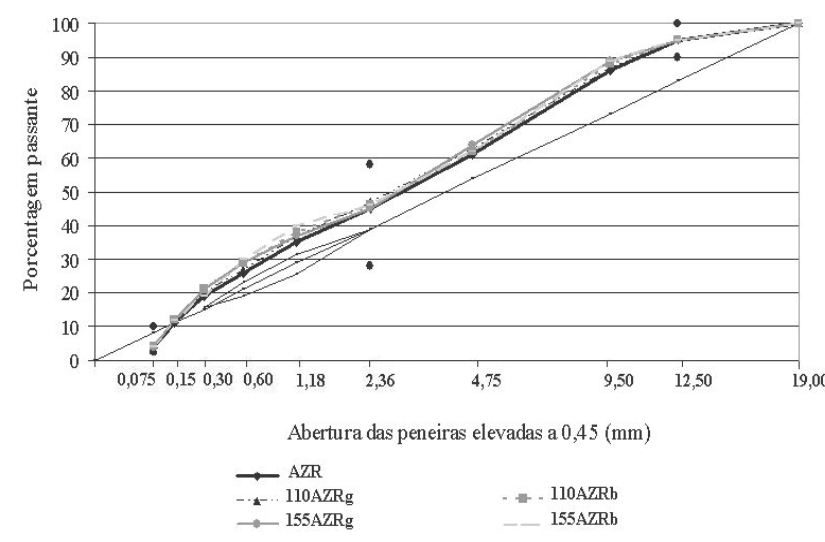

Figura 4. Curvas AZRg e AZRb obtidas após compactação e curva AZR de projeto

aumento da energia de compactação de 110 para 155 golpes não alterou significativamente as porcentagens de quebra.

Resultados similares quando à quantidade reduzida de quebra de devido ao aumento da energia de compactação aplicada também foram obtidos por Albuquerque (2005) e Carneiro \& Silva (1979).

\subsection{Propriedades de forma, de angularidade e de textura superficial dos agregados}

$\mathrm{Na}$ Tabela 2, estão apresentados os resultados das porcentagens de faces fraturadas do agregado grosso (AAG); grau de angularidade do agregado grosso $\left(\mathrm{GA}_{\mathrm{ag}}\right)$; porcentagem de partículas planas $(\mathrm{PP})$, de partículas alongadas (PA) e de partículas planas e alongadas (PP\&A) do agregado grosso, avaliadas na proporção de $3: 1$, por esta caracterizar mais realisticamente as formas do agregado (Gouveia \& Fernandes Jr., 2006) e textura superficial. Também estão apre-

Tabela 2. Propriedades de forma e angularidade dos agregados de gabro e basalto

\begin{tabular}{lcc}
\hline Propriedades & Gabro & Basalto \\
\hline $\mathrm{AAG}$ & $100 / 100 \%$ & $100 / 100 \%$ \\
$\mathrm{GA}_{\mathrm{ag}}$ & subangular & angular \\
$\mathrm{PP}(3: 1)$ & $0,8 \%$ & $5,2 \%$ \\
$\mathrm{PA}(3: 1)$ & $0,1 \%$ & 0,0 \\
PP\&A (3:1) & $5,6 \%$ & $18,3 \%$ \\
Textura Superficial & rugosa & rugosa \\
$\mathrm{AAF}$ & 48,3 & 51,1 \\
$\mathrm{GA}_{\mathrm{af}}$ & subangular & angular \\
$\mathrm{GE}_{\mathrm{af}}$ & 0,84 & 0,65 \\
\hline
\end{tabular}

Tabela 3. Propriedades volumétricas para energias de compactação de 75, 110 e 155 golpes

\begin{tabular}{|c|c|c|c|c|c|c|c|c|c|c|c|c|c|c|c|}
\hline \multirow[b]{3}{*}{ Misturas } & \multicolumn{6}{|c|}{ Propriedades das Misturas } & \multicolumn{9}{|c|}{ Propriedades Volumétricas } \\
\hline & \multicolumn{3}{|c|}{$A_{\text {ef }}(\%)$} & \multicolumn{3}{|c|}{ d } & \multicolumn{3}{|c|}{ VAM (\%) } & \multicolumn{3}{|c|}{ RBV (\%) } & \multicolumn{3}{|c|}{ Vv (\%) } \\
\hline & 75 & 110 & 155 & 75 & 110 & 155 & 75 & 110 & 155 & 75 & 110 & 155 & 75 & 110 & 155 \\
\hline AZRg & 5,3 & 5,2 & 5,0 & 2,423 & 2,435 & 2,445 & 17,0 & 16,5 & 16,0 & 74,5 & 74,9 & 74,5 & 4,3 & 4,1 & 4,1 \\
\hline $\mathrm{AZRb}$ & 6,5 & 6,0 & 5,6 & 2,467 & 2,490 & 2,507 & 19,5 & 18,3 & 17,4 & 80,2 & 79,3 & 78,4 & 3,9 & 3,8 & 3,8 \\
\hline
\end{tabular}

sentados os resultados da angularidade do agregado fino (AAF), representativos da forma, angularidade e textura superficial de maneira conjunta; grau de angularidade do agregado fino $\left(\mathrm{GA}_{\mathrm{af}}\right)$ e grau de esfericidade do agregado fino $\left(\mathrm{GA}_{\mathrm{af}}\right)$.

Os resultados apresentados indicam que o agregado de gabro possui todas as suas partículas grossas com duas ou mais faces fraturadas, com cantos e arestas, tanto da fração grossa quanto fina, apresentando desgaste incipiente (subangularidade), e partículas com formas quase esféricas, com textura superficial rugosa. O agregado de basalto apresenta todas as suas partículas grossas com duas ou mais faces fraturadas, com cantos e arestas, tanto da fração grossa quanto fina, agudos, não apresentando sinais de desgaste nem presença de partículas com formas planas, e, textura superficial rugosa.

\subsection{Propriedades volumétricas}

Os resultados das propriedades volumétricas, correspondentes à média entre aproximadamente 25 corpos de prova compactados com 75, 110 e 155 golpes do soquete Marshall, estão apresentados na Tabela 3, assim como o teor de asfalto efetivo $\left(\mathrm{A}_{\mathrm{ef}}\right)$ e a densidade aparente das misturas compactadas. Pode-se observar que com a elevação da energia de compactação houve uma diminuição do VAM, ou seja, as partículas de agregado arranjaram-se de maneira mais próxima. Vale mencionar que todas as misturas apresentaram VAM acima do limite mínimo de $16 \%$ recentemente especificado pelo DNIT 031/2004-ES.

A mistura AZRb, que apresentava o maior valor de VAM quando compactada com energia de 75 golpes, teve o maior decréscimo no valor do VAM com a elevação da energia de compactação aplicada. Essa sensível diminuição do VAM é indicativa do aumento da densidade relativa da mistura. Já a mistura AZRg, que não apresentava VAM tão elevado quanto o da mistura AZRb, teve aproximação entre suas partículas, porém, não tão acentuada.

\subsection{Estabilidade e fluência Marshall}

Os resultados mostram que com a elevação da energia de compactação ocorre ganho de estabilidade (Tabela 4). O aumento da energia de compactação de 75 golpes para 110 golpes representou um ganho de esta- 
Tabela 4. Estabilidade (E) e fluência (F) Marshall para energias de compactação de 75, 110 e 155 golpes

\begin{tabular}{cccc|ccc}
\hline \multirow{2}{*}{ Misturas } & \multicolumn{1}{c|}{$\boldsymbol{E}(\boldsymbol{N})$} & \multicolumn{3}{c}{$\boldsymbol{F}(\mathbf{0 , 1 m m})$} \\
\cline { 2 - 7 } & $\mathbf{7 5}$ & $\mathbf{1 1 0}$ & $\mathbf{1 5 5}$ & $\mathbf{7 5}$ & $\mathbf{1 1 0}$ & $\mathbf{1 5 5}$ \\
\hline AZRg & 17583 & 22080 & 28924 & 42 & 38 & 37 \\
Desvio-padrão & 531 & 873 & 1026 & 1 & 3 & 1 \\
\hline AZRb & 12837 & 16981 & 19299 & 44 & 44 & 43 \\
Desvio-padrão & 873 & 325 & 219 & 2 & 2 & 1 \\
\hline
\end{tabular}

bilidade em torno de $20 \%$ para a mistura AZRg e de $24 \%$ para a mistura AZRb. Já, a elevação da energia de compactação de 110 para 155 golpes, resultou em ganho de estabilidade de $24 \%$ para a mistura AZRg e de $12 \%$ para a mistura AZRb.

Os ganhos de estabilidade observados devem-se, provavelmente, à energia de compactação adicional ter vencido a resistência à compactação promovida pelas partículas angulosas e rugosas, tornando possível a formação de arranjos mais densos, constatados através da diminuição do VAM (Tabela 3), culminado em misturas com esqueletos estruturais mais resistentes. Essa afirmação corrobora os resultados obtidos através do ensaio de fluência por compressão uniaxial dinâmica, apresentados mais adiante. A fluência Marshall das misturas não sofreu variação estatisticamente significativa com o aumento da energia de compactação.

\subsection{Fluência por compressão uniaxial dinâmica}

$\mathrm{Na}$ Tabela 5, estão apresentados os valores médios, referentes a três determinações, de deformação total (5000s), módulo de fluência (tensão aplicada/deformação após 5000s) e inclinação nos trechos entre 100 e 5000s da curva de fluência e desvios padrão.

Os resultados referentes à mistura AZRg mostram que com o aumento da energia de compactação de 75 para 110 golpes houve redução da deformação total em torno de $39 \%$, aumento do módulo de fluência em

Tabela 5. Ensaio de fluência por compressão uniaxial dinâmica para energias de compactação de 75, 110 e 155 golpes

\begin{tabular}{lccc}
\hline Misturas & $\begin{array}{c}\boldsymbol{D t} \\
(\mathbf{m m} / \mathbf{m m})\end{array}$ & $\begin{array}{c}\boldsymbol{M F} \\
(\boldsymbol{M P a})\end{array}$ & Incli. \\
\hline 75AZRg & 0,00267 & 38,37 & 0,34798 \\
Desvio-padrão & 0,00036 & 3,36 & 0,02520 \\
110AZRg & 0,00163 & 74,93 & 0,27692 \\
Desvio-padrão & 0,00015 & 5,47 & 0,01462 \\
155AZRg & 0,00066 & 174,38 & 0,18435 \\
Desvio-padrão & 0,00007 & 20,79 & 0,02317 \\
\hline 75AZRb & 0,00351 & 32,09 & 0,34633 \\
Desvio-padrão & 0,00024 & 2,83 & 0,02450 \\
110AZRb & 0,00161 & 67,59 & 0,29953 \\
Desvio-padrão & 0,00027 & 14,32 & 0,03184 \\
155AZRb & 0,00068 & 166,74 & 0,16015 \\
Desvio-padrão & 0,00004 & 7,21 & 0,00859 \\
\hline
\end{tabular}

aproximadamente $49 \%$ e redução da inclinação da curva de fluência em aproximadamente $20 \%$. Já a elevação da energia de 110 para 155 golpes melhorou a capacidade da mistura AZRg de resistir à deformação permanente, pois a deformação total diminuiu aproximadamente $60 \%$, o módulo de fluência aumentou cerca de $60 \%$ e a inclinação da curva de fluência diminuiu 33\%. Semelhante ganho de resistência quanto à deformação permanente foi obtido na produção de misturas com agregado de basalto ao elevar a energia de compactação de 75 para 110 e de 110 para 155 golpes.

\subsection{Resistência à tração e módulo de resiliência}

Na Tabela 6, estão apresentados os valores médios, referentes a três determinações, da resistência à tração por compressão diametral (RT) e do módulo de resiliência (MR).

A resistência à tração das misturas variou conforme a energia de compactação aplicada. A elevação da energia de compactação de 75 para 110 golpes gerou ganho de resistência à tração em torno de $35 \%$, enquanto que de 110 para 155 golpes o ganho de resistência foi de aproximadamente $10 \%$. Já nas misturas produzidas com basalto, a elevação da energia de compactação de 75 para 110 golpes proporcionou ganho de resistência à tração em torno de $20 \%$, enquanto que de 110 para 155 golpes o ganho foi de $11 \%$.

\subsection{Vida de fadiga - análise mecanística}

Análises comparativas quanto às estimativas de vida

Tabela 6. Ensaio de fluência por compressão uniaxial dinâmica para energias de compactação de 75, 110 e 155 golpes

\begin{tabular}{lcc}
\hline Misturas & RT (MPa) & MR (MPa) \\
\hline 75AZRg & 1,36 & 5410 \\
Desvio-padrão & 0,05 & 182 \\
110AZRg & 2,12 & 12130 \\
Desvio-padrão & 0,02 & 917 \\
155AZRg & 2,35 & 19016 \\
Desvio-padrão & 0,01 & 1893 \\
\hline 75AZRb & 1,35 & 5146 \\
Desvio-padrão & 0,04 & 150 \\
110AZRb & 1,69 & 7282 \\
Desvio-padrão & 0,02 & 787 \\
155AZRb & 1,90 & 11011 \\
Desvio-padrão & 0,03 & 1494 \\
\hline
\end{tabular}


de fadiga foram realizadas tendo como referência uma mesma estrutura de pavimento utilizada para cálculo de respostas estruturais (tensões e deformações) na base da camada asfáltica e, na seqüência, para a determinação do número de solicitações admissíveis ou vida de fadiga de cada mistura.

Foi utilizado o programa computacional Elsym5 que considera o pavimento como um sistema elástico tridimensional de camadas sobrepostas e os materiais como sendo isotrópicos e homogêneos com comportamento elástico-linear, obedecendo à lei de Hooke generalizada.

Dois perfis estruturais serviram como referência para estimar a vida de fadiga. Ambos são compostos por quatro camadas, porém, cada perfil fora idealizado com níveis de rigidez diferentes, como se pode observar na Figura 5.

Nas Figura 6 e 7, estão ilustradas as curvas de fadiga das misturas produzidas com agregado de gabro e de basalto compactadas com energias de 75, 110 e 155 golpes por face. Analisando as inclinações das curvas de fadiga em função da variação da energia de compactação aplicada, pode-se observar que as misturas produzidas com gabro apresentaram inclinações entre 3,81 e 5,10 , cuja menor inclinação ocorreu para a mistura 155AZRg $(3,81)$ (Figura 6). Já as misturas com basalto apresentaram inclinações bastante próximas para os três níveis de energias de compactação aplicadas, com n variando entre 3,33 e 3,79 (Figura 7).

$\mathrm{Na}$ Tabela 8 , estão apresentados os parâmetros do ensaio de fadiga ( $\mathrm{k}$ e $\mathrm{n}$ ), assim como a diferença de tensões de tração e compressão $(\Delta \sigma)$, calculadas computacionalmente através do programa Elsym5 para as estruturas hipotéticas (Figura 5), e a vida de fadiga $(\mathrm{N})$.



(a) Estrutura 1

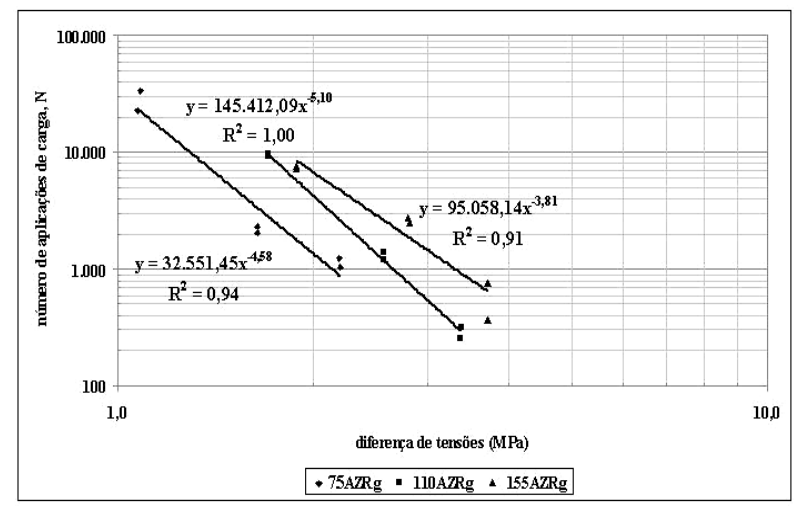

Figura 6: Curvas de fadiga das misturas produzidas com agregado de gabro com energias de compactação de 75, 110 e 155 golpes por face

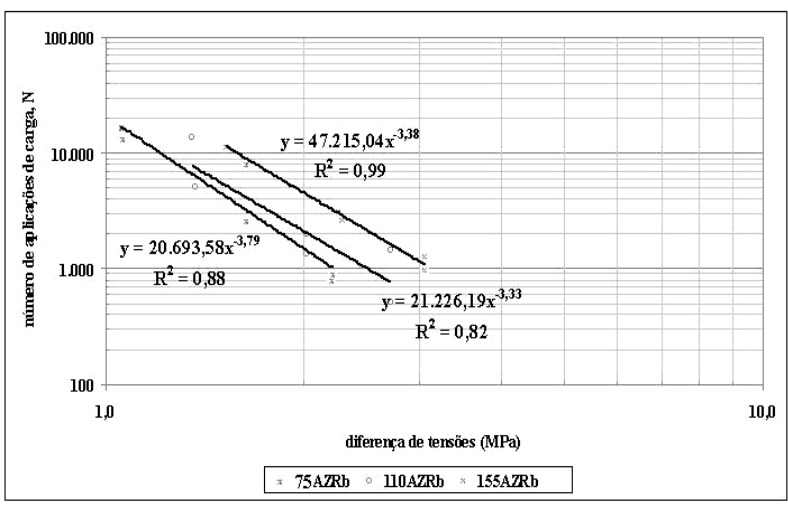

Figura 7: Curvas de fadiga das misturas produzidas com agregado de basalto com energias de compactação de 75,110 e 155 golpes por face

Os resultados da vida de fadiga versus número de golpes empregados na compactação das misturas estão ilustrados nos gráficos apresentados na Figura 8. Pode-se depreender que a elevação da energia de compactação de 75 para 110 golpes proporcionou um aumento da vida de fadiga da mistura 110AZRg em cerca de 2,5 vezes e que a elevação da energia de com-

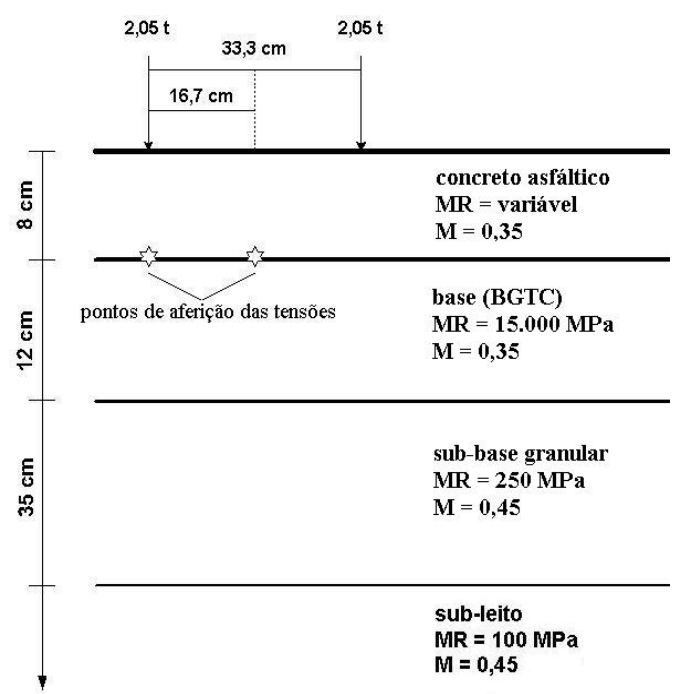

(b) Estrutura 2

Figuras 5: Estruturas utilizadas, características e localização do carregamento e pontos de aferição das tensões 
Tabela 8. Ensaio de fluência por compressão uniaxial dinâmica para energias de compactação de 75, 110 e 155 golpes

\begin{tabular}{|c|c|c|c|c|c|c|c|}
\hline \multirow[t]{2}{*}{ Misturas } & \multirow[t]{2}{*}{$M R(M P a)$} & \multirow[t]{2}{*}{$R T(M P a)$} & \multirow[t]{2}{*}{$M R / R T$} & \multicolumn{4}{|c|}{$N=k\left(\frac{1}{\Delta \sigma}\right)^{n}$} \\
\hline & & & & $\boldsymbol{k}$ & $n$ & $\Delta \sigma$ & $N$ \\
\hline $75 \mathrm{AZRg}$ & 5.410 & 1,36 & 3.972 & 32.552 & 4,58 & 0,14 & $3,0 \times 10^{8}$ \\
\hline 110AZRg & 12.130 & 2,12 & 5.735 & 145.412 & 5,10 & 0,19 & $7,6 \times 10^{8}$ \\
\hline $155 \mathrm{AZRg}$ & 19.016 & 2,35 & 8.098 & 95.058 & 3,81 & 0,15 & $1,2 \times 10^{8}$ \\
\hline $75 \mathrm{AZRb}$ & 5.146 & 1,35 & 3.809 & 20.694 & 3,79 & 0,17 & $1,8 \times 10^{7}$ \\
\hline $110 \mathrm{AZRb}$ & 7.282 & 1,69 & 4.306 & 21.226 & 3,33 & 0,22 & $3,4 \times 10^{7}$ \\
\hline $155 \mathrm{AZRb}$ & 11.011 & 1,90 & 5.809 & 47.215 & 3,38 & 0,20 & $1,2 \times 10^{7}$ \\
\hline
\end{tabular}

pactação de 110 para 155 golpes ocasionou um decréscimo da vida de fadiga da mistura 155AZRg de aproximadamente 6 vezes (Figura 8a).

O mesmo comportamento, quanto à variação da vida de fadiga em função da energia de compactação, foi observado para as misturas produzidas com basalto (Figura 8b). A elevação da energia de compactação de 75 para 110 golpes fez com que a vida de fadiga da mistura 110AZRb praticamente dobrasse; mas a mistura compactada com 155 golpes teve sua vida de fadiga diminuída em aproximadamente 3 vezes.

Os resultados indicam que tanto as misturas com gabro quanto as misturas com basalto tiveram comportamento melhor à fadiga quando compactadas com 110 golpes por face. No entanto, resultados também satisfatórios quanto à fadiga foram observados com energias de compactação de 75 e de 155 golpes.

Portanto, a escolha do nível de energia de compactação a ser empregado dependerá das características de tráfego da rodovia e/ou do local de aplicação das misturas (por exemplo, pátio de estacionamento de caminhões, corredor de ônibus, etc.). Como visto, misturas produzidas com 110 golpes mostraram excelente resistência à fadiga e boa resistência à deformação permanente, enquanto misturas produzidas com 155 golpes apresentaram excelente resistência à deformação permanente e boa resistência à fadiga.

\section{CONCLUSÕES}

Esta pesquisa teve por objetivo avaliar a influência do

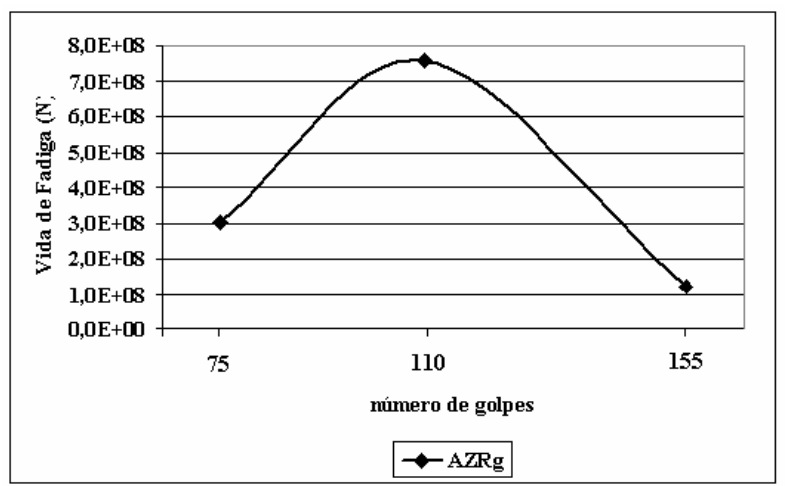

(a) grau de compactação sobre propriedades volumétricas e mecânicas de misturas asfálticas, variando-se gradativamente a energia de compactação de 75 golpes para 110 golpes e, então, para 155 golpes, aplicados pelo soquete Marshall. Estudos foram desenvolvidos com base na hipótese de que as misturas produzidas com agregados angulares e rugosos, mais difíceis de serem compactados, poderiam ser compactadas com maior energia, de modo a reduzir o VAM e melhorar o arranjo estrutural formado entre partículas.

Os resultados mostram que as características volumétricas e mecânicas das misturas são alteradas em função da energia de compactação aplicada. Ao empregar energias de compactação mais elevadas, as partículas angulosas e rugosas dos agregados de gabro e de basalto estudados arranjam-se de maneira mais próxima, permitindo a diminuição do VAM, e, conseqüentemente, a elevação da estabilidade e rigidez das misturas, sem causar prejuízos à vida de fadiga, pelo contrário, a vida de fadiga aumentou com a elevação da energia de 75 para 110 golpes.

Pode-se concluir, portanto, que a hipótese de aumento da energia de compactação em misturas produzidas com agregados angulosos e rugosos com resistência adequada parece promissora. Espera-se que o presente trabalho incentive a realização de outros estudos buscando uma maior abrangência em relação à amostragem de agregados e análises de desempenho das misturas em campo no país.

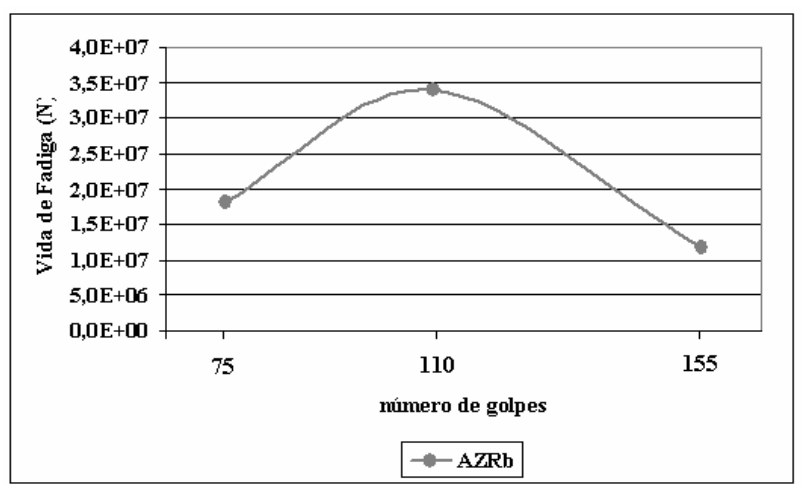

(b)

Figura 8: Variação da vida de fadiga das misturas produzidas com gabro (a) e com basalto (b), em função da energia de compactação aplicada 


\section{AGRADECIMENTOS}

Agradecimentos à Fapesp pelo apoio financeiro na forma de bolsa de doutorado.

\section{REFERÊNCIAS BIBLIOGRÁFICAS}

Albuquerque, A.P.F. (2005) Influência da energia e da temperatura de compactação nos parâmetros volumétricos e nas propriedades mecânicas dos concretos asfálticos. Dissertação de Mestrado, Ministério da Defesa-IME.

ABNT NBR 12891 (1993) Dosagem de Misturas Betuminosas pelo Método Marshall. Associação Brasileira de Normas Técnicas.

AASHTO PP2 (1990) Standard Practice for Mixture Conditioning of Hot Mix Asphalt. American Association of State Highway and Transportation Officials

AASHTO T 166 (1990) Bulk Specific Gravity of Compacted Bituminous Mixtures using Saturated Surface-Dry Specimens. American Association of State Highway and Transportation Officials.

Anderson, R.M.; Bahia, H.U (1997) Evaluation and selection of aggregate gradations for asphalt mixtures using Superpave. Transportation Research Record, n. 1583, p. 91-97.

ABNT NBR 12891 (1993). Dosagem de Misturas Betuminosas pelo Método Marshall. Associação Brasileira de Normas Técnicas.

Carneiro, F.B.L.; Silva, H.C.M. (1979) Degradação dos agregados nas camadas de base de brita graduada e de revestimento de concreto asfáltico. $4^{\circ}$ Encontro de Asfalto, IBP.

Cross, S.A.; Brown, E.R. (1992) Selection of Aggregate Properties to Minimize Rutting of Heavy Duty Pavements. In: Effects of Aggregates and Mineral Fillers on Asphalt Mixture Performance. American Society for Testing and Materials.

DNER ME 138 (1994) Misturas Betuminosas - Determinação da resistência à tração por compressão diametral. Departamento Nacional de Estradas de Rodagem.

DNIT 031/2004-ES (2004) Pavimentos Flexíveis-Concreto AsfálticoEspecificação de serviço, Departamento Nacional de Infraestrutura de Transportes.

Gouveia, L.T. (2006) Contribuições ao estudo da influência de propriedades de agregados no comportamento de misturas asfálticas densas. Tese de Doutorado, EESC-USP.

Kandhal, P.S.; Cooley Jr., L.A. (2001) The restricted zone in the Superpave aggregate gradation specification. National Cooperative Highway Research Program, n. 464.

Kim, Y.R.; Kim, N.; Khosla, N.P. (1992) Effects of aggregate type and gradation on fatigue and permanent deformation of asphalt concrete. In: Effects of Aggregates and Mineral Fillers on Asphalt Mixture Performance. American Society for Testing and Materials.

Mahmoud, A.F.F; Bahia, H. (2004) Using the gyratory compactor to measure mechanical stability of asphalt mixtures. Wisconsin Highway Research Program-WHRP 05-02

Masad, E.; Muhunthan, B.; Shashidhar, N.; Harman, T. (1999) Internal Structure Characterization of Asphalt Concrete Using Image Analysis. Journal of Computing in Civil Engineering, v. 13, $\mathrm{N}^{\circ} 2$.

Suguio, K. (1973). Introdução à Sedimentologia. Edgard Blucher Ltda./Universidade de São Paulo. São Paulo, SP.

Yue, Z.Q.; Bekking, W.; Morin, I. (1995) Application of Digital Image Processing to Quantitative Study of Asphalt Concrete Microstructure. Transportation Research Record 1492, p. 53-60. 